\title{
Online Learning and Students' Fear of COVID-19: Study in Malaysia and Pakistan
}

Farhat Munir ${ }^{1, \dagger}$, Aizza Anwar ${ }^{1,2, \dagger^{*}, \text { and Daisy Mui Hung Kee }}{ }^{2}$

1 University of Management and Technology, University of Management and Technology, Lahore, Pakistan; 2Universiti Sains Malaysia, Penang, Malaysia

tFirst Authorship Shared

${ }^{*}$ Corresponding Author

\begin{abstract}
The COVID-19 pandemic has forced millions of students to stay indoors and adapt to the new normal, namely distance learning at home, placing online learning in the spotlight. However, students' motivation for online learning and its effectiveness in skill development during the COVID-19 pandemic has not been widely studied. This study examined the relationship between students' fear of COVID-19 and students' social presence in online learning while investigating the parallel mediating role of student psychological motivation and cognitive problem-solving skills related to online learning. The participants were 472 university students in Malaysia and Pakistan. An online data collection technique using Google Forms was employed. Faculty members of the universities were asked to share the survey with their students. Moreover, using a snowball sampling technique, students were requested to share the survey with their friends. SPSS Statistics (Version 21) was employed to do preliminary data analysis, AMOS (Version 21) software was used to conduct confirmatory factor analysis using a maximum likelihood estimation, and Hayes' PROCESS model was used to examine proposed hypotheses. The results show that only cognitive problem solving mediates the relationship between fear of COVID-19 and students' social presence in online learning in Malaysian samples. In Pakistan, cognitive problem solving and psychological motivation mediate the relationship between fear of COVID-19 and students' social presence in online learning. The study found that developing cognitive problem-solving skills and providing psychological motivation could enhance their engagement with online learning.
\end{abstract}

Keywords: fear of COVID-19, social presence, cognitive problem-solving skills, psychological motivation, online learning, Pakistan, Malaysia 


\section{Introduction}

The COVID-19 pandemic has hit the education industry due to the prevailing lockdown measures in some countries. Lockdown and movement restrictions have caused unprecedented challenges for students due to the abrupt transition to online learning. Students have been forced to stay indoors and adapt to online learning. To capture the immediate economic effects of the pandemic, UK universities alone, for example, incurred an estimated cost of $£ 790$ million due to the COVID-19 pandemic, and universities resorted to online teaching and learning until the advent of a successful vaccine (Daniel, 2020). The pandemic has increased the importance of online teaching and learning in both developed (Dost et al., 2020) and developing countries (Dashtestani, 2020). This has resulted in a pedagogical shift to increase students' psychological motivation and cognitive problem-solving skills (CPSS) in order to improve sustainable engagement in online learning (Lee et al., 2019). Students with a higher perceived social presence in an online environment experience a greater degree of learning satisfaction and engagement (Grieve et al., 2016).

The pandemic has had a significant effect on students' lives. Public health measures such as social distancing, movement restrictions, and lockdown are necessary to minimize the spread of COVID-19. These measures have put students under psychological distress (Hasan \& Bao, 2020), and some are experiencing fear of COVID-19, depression, anxiety, and stress (Kassim et al., 2021). Apart from the devastating health consequences, the pandemic affects students' physical and mental well-being (Zolotov et al., 2020).

Fear of COVID has been reported in different countries. An Iranian study on 717 Iranians measured their fear at 3.9 on a scale of 5 (Chang et al., 2020). A Bangladeshi study on 8,550 individuals reported similar results, measuring their fear at 3.1 out of 5 (Sakib et al., 2020). The findings have revealed that the fear of COVID-19 differs in terms of its intensity and scale across countries. One study argued that cultural differences (Pramukti et al., 2020) could be playing a significant role in students' perceptions of fear of COVID-19.

Although rigorous research has been done on the online environment for teaching and learning, how fear of COVID-19 influences students' online learning is a research gap at almost all education levels (Al-Maroof et al., 2020), but especially at higher education. Our research addressed two questions:

1. What effect does students' perceived fear of COVID-19 on students' social presence in online learning?

2. How do psychological motivation and cognitive problem-solving skills mediate the relationship between fear of COVID-19 and students' social presence in online learning?

To investigate this assumption, we selected two countries of Asia (Malaysia and Pakistan) having similar experiences during the pandemic to see how students experience fear of COVID-19 and how it has affected their social presence in online learning. Moreover, we examined how their psychological motivation related to online learning and the CPSS they developed during online learning mediated between their fear of COVID-19 and their social presence in online learning.

\section{Theoretical Background}

This study is based on constructivists' theory, emphasizing that knowledge is constructed based on learners' interpretations of experiences in the world (Jonassen \& Rohrer-Murphy, 1999). It suggests 
that learning is an active process and that all knowledge is unique to each individual focused on knowledge construction, critical thinking, and problem-solving. The community of inquiry (COI) framework is structuring the process of learning in an online environment. It elaborates on the essential elements of a successful online learning experience in higher education. The cognitive presence outlines the process of learning. Teaching covers the design of the course and guidance, and it also influences the social presence learning experience (Stenbom, 2018). It is observed that CPSS learned online give students opportunities to solve real-life problems, whereas psychological motivation determines the satisfaction level of students' online learning. The social constructivism approach argues that all learning results from social interaction. Thus, a students' social presence during online learning helps them learn as they collaborate with peers under their teachers' instructions (Stenbom, 2018). This approach towards learning refines their ability to solve problems (Amin \& Mariani, 2017), organize information, and make decisions (McWhirter \& Shealy, 2020). These skills are significant in higher education, and applicable to becoming a successful professional (Songkram et al., 2015).

\section{Literature Review}

\section{Online Learning and Fear of COVID-19}

Fear of COVID-19 has become a threat to physical and mental health for human beings worldwide (Huang et al., 2020). It has extended or caused several other fears, e.g., loss of life, career, education, and fear of adopting technologies for online learning (Al-Maroof et al., 2020). The pandemic situation has forced educational institutes to abruptly switch from traditional on-campus to online modes of teaching and learning, and this has instigated fears among students as the unavailability of resources was one of the critical factors, especially for those who had no experience using these resources for online learning (Al-Maroof et al., 2020). The intensity of this fear can be estimated by the reports on student suicide in different countries (Mamun \& Griffiths, 2020). Such reports demonstrated several fears associated with the situation that made it difficult for students to cope. However, these reports also encouraged us to determine the impact of fear of COVID-19 on students' social presence and examine how it influences the quality of virtual interactions and outcomes (Bickle et al., 2019).

\section{Social Presence and Online Learning}

Social presence is an essential component of students' satisfaction with online learning (Shea et al., 2001). It is described as "the degree to which a person is perceived to be a 'real person' in his/her technologically mediated communication or virtual environments" (p. 383), and the level of social presence influences the quality of virtual interactions and outcomes (Bickle et al., 2019). This aspect is considered a prominent indicator of students' motivation since, when they are engaged with instructors and peers, their responses are being valued, their queries are being addressed, and they feel more engaged and motivated (Woods \& Baker, 2004).

The prevailing situation has increased the importance of quality education and created a debate among academics about how to improve the quality of online education to improve the efficiency of students' learning, as well as their motivation and satisfaction in a situation like COVID-19. The researchers have considered social presence to be an emotional aspect of students' motivation (Stodel et al., 2006) and satisfaction (Shapiro et al., 2017), generally expressed in classroom discussions. 
The COVID-19 pandemic has caused several challenges for online education, put a question mark on the online technological resources, and made effective online learning an uphill task. Limited research is available on how fear of pandemics like COVID-19 influences students' social presence in online learning. The study becomes particularly important in a situation of extreme fear of COVID-19 when stress, anxiety, and phobias become more intense because of decreased social interaction due to protocols such as social distancing, lack of emotional support, and physical isolation, and further cast adverse psychological effects on students (Elmer et al., 2020). This research gap becomes more critical to explore when we see it in the context of the constructivist point of view that students first construct knowledge by interacting with peers and then adopt the knowledge (Romero et al., 2014). The following hypothesis was developed to address the first research question.

- $\mathrm{H}_{1}$ : Students' fear of COVID-19 is positively related to students' social presence in online learning

\section{Students' Cognitive Problem-Solving Skills}

In cognitive psychology, the term problem-solving refers to the mental process that people go through to discover, analyze, and solve problems. It is argued (Noordegraaf-Eelens et al., 2019) that it is the mission of all educational institutions, no matter what level, to impart knowledge and develop cognitive problem-solving skills. Preparing learners with CPSS has become one of the components of quality teaching and the quality of any school depends on how well it has developed cognitive problem-solving skills in its learners (Borghans et al., 2015).

Cognitive problem-solving skills are also imperative to success in a career (Romero et al., 2014). CPSS assists learners in making independent decisions and solving problems (Zoller \& Pushkin, 2007). They allow individuals to adapt to new situations and solve new problems by applying their knowledge (Masalimova et al., 2019). Therefore, it has become imperative for educational institutions, especially those of higher education, to prepare students to face contemporary situations, regulate their emotions, and demonstrate self-determination. This paper argues that students' CPSS will better equip them to handle transitions and life changes, and perform smoothly with resilience.

Several research studies on the significance of CPSS, but how it mediates between an extreme and new situation, such as the COVID-19 pandemic and students' social presence in online learning, is unknown. During the fearful situation of the pandemic, students have coped with COVID-19-related stress differently. Some students have adjusted or coped with the stressors well and demonstrated effective social presence in online learning, while others have been fearful and exhibited ineffective social presence. Seeing this gap in research, the following hypothesis was developed to address the second research question.

- $\mathrm{H}_{2}$ : Cognitive problem-solving skills mediate the relationship between fear of COVID-19 and students' social presence in online learning.

\section{Students' Psychological Motivation and Online Learning}

Psychological motivation in online learning is one of the core components of academic engagement and encourages students to achieve some goals (Oudeyer et al., 2016). The education sector is considered a driving force that leads students to learn (Martin, 2008) and achieve academic targets (Liu et al., 2012). A large body of research is available on traditional learning environments (Bekele, 2010), and there is evidence that the transition from traditional to remote learning during the COVID-19 pandemic was 
successful (Basilaia \& Kvavadze, 2020). However, minimal literature is available on the quality and effectiveness of online learning, improving student learning outcomes (Baber, 2021), and no research is available on how fear of the pandemic affects students' motivation in online learning.

Anxieties and stress are also explored as challenges for effective online learning (Adedoyin \& Soykan, 2020; Mubarak et al., 2020), but how this inner force mediates between the extreme fear of a pandemic and students' social presence at the higher education level presents a gap in the research. Therefore, to address the research gap and second research question, the following hypothesis was developed.

- $\mathrm{H}_{3}$ : Psychological motivation mediates the relationship between fear of COVID-19 and students' social presence in online learning.

The theoretical framework is shown in Figure 1.

\section{Figure 1}

\section{Theoretical Framework}

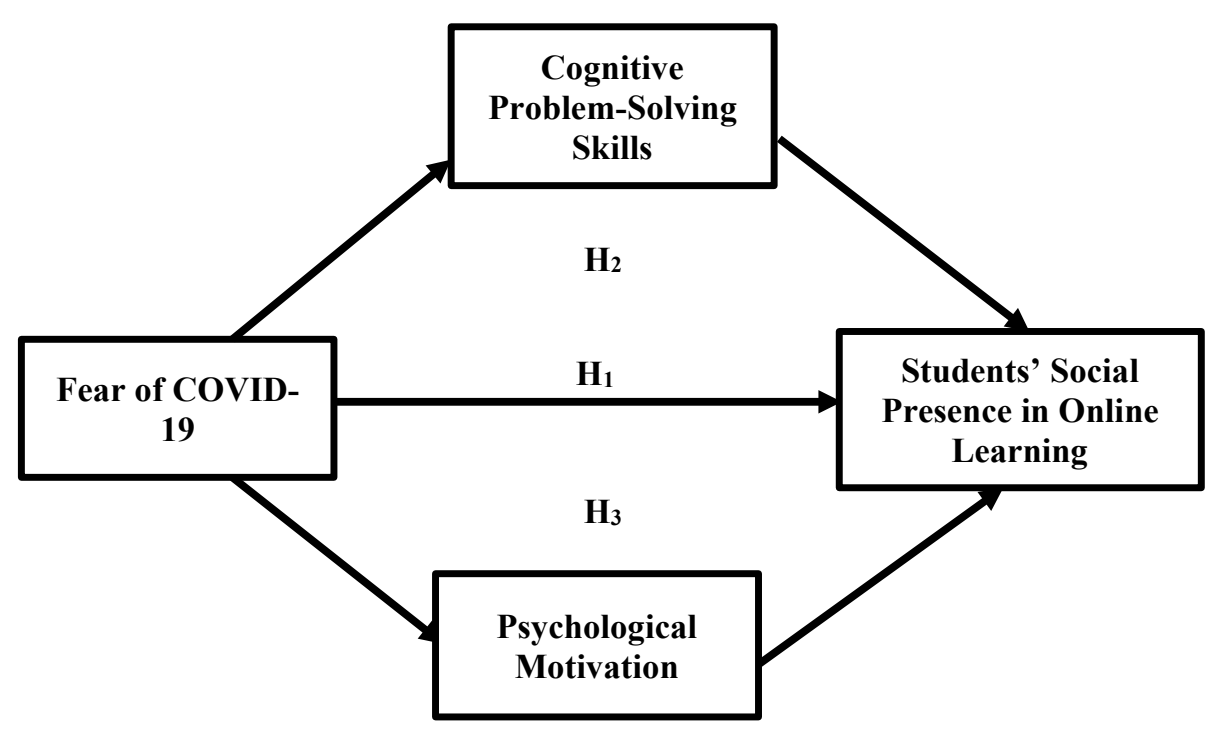

\section{Methodology}

\section{Sample}

A quantitative descriptive correlational research design was applied in this study. The data were collected online using Google Forms in both countries because students were physically unavailable on campus. The authors contacted faculty members of their universities and asked them to share the survey with their students. Moreover, a snowball sampling technique was used; students were requested to share the survey with their friends. The sample consisted of 214 student responses from Malaysia's universities and 258 student responses from Pakistan's universities. In Malaysia, the majority of participants were undergraduate and second-year female students ( 158 female, $73.8 \%$ ) with a mean age of $22.82(S D=8.91)$, while in Pakistan, the majority were master's and second-year male students (130 male, 50.4\%) with a mean age of $24.47(S D=5.24)$. Students were informed of the purpose of the study, 
and their participation was entirely voluntary. They were assured that responses were used for academic research purposes. Students were asked to complete the online survey via Google Forms.

\section{Measures}

The study used established scales, written in English, in both studies. The measures are defined below and all items in the survey are shown in Appendix 1.

Students' social presence in online learning (SPOL) was measured using 14 items developed by Strong (2012). This variable measures students' comfort level in online course discussions. A sample item is: "computer-mediated communication is an excellent medium for social interaction." Responses ranged from 1 (never) to 5 (often).

Psychological motivation (PM) was measured using six items from a scale developed by Lee et al. (2019). This variable measures student interest in online classes. A sample item is: "online classes are very useful to me," measured, again, on a 5-point Likert scale ranging from 1 (strongly disagree) to 5 (strongly agree).

Cognitive problem-solving skills (CPSS) were measured using five items (Lee et al., 2019). This variable measures a student's current level of skills developed during online learning. The sample item of CPSS is: "I can deeply analyze thoughts, experiences, and theories about the knowledge I have learned in my online classes." The data was again collected using a 5-point Likert scale, ranging from 1 (strongly disagree) to 5 (strongly agree).

Fear of COVID-19 (FCoV) was measured by seven items (Ahorsu et al., 2020). A sample item of this scale is: "I am most afraid of COVID-19." The responses were collected on a 5-point Likert scale ranging from 1 (strongly disagree) to 5 (strongly agree).

\section{Results}

Table 1 shows that $63 \%$ of the Malaysian and $51 \%$ of the Pakistani students were fearful about COVID19. In general, it may be said that the participants in both countries have been strongly affected by the pandemic.

\section{Table 1}

Analysis of Fear of COVID-19 Experienced by University Students of Pakistan and Malaysia

\begin{tabular}{lcc}
\hline \multicolumn{1}{c}{ Item } & $\begin{array}{c}\text { Pakistan } \\
(\%)\end{array}$ & $\begin{array}{c}\text { Malaysia } \\
(\%)\end{array}$ \\
\hline I am most afraid of COVID-19. & 51.2 & 63.1 \\
It makes me uncomfortable to think about COVID-19. & 55.7 & 44.9 \\
My hands become clammy when I think about COVID-19. & 29.2 & 15.4 \\
I am afraid of losing my life because of COVID-19. & 38.3 & 48.6 \\
\hline
\end{tabular}




\begin{tabular}{|c|c|c|}
\hline $\begin{array}{l}\text { When watching news and stories about COVID-19 on social media, I } \\
\text { become nervous or anxious. }\end{array}$ & 61.5 & 33.1 \\
\hline I cannot sleep because I am worried about getting COVID-19. & 21.1 & 6.1 \\
\hline My heart races or palpitates when I think about getting COVID-19. & 31.8 & 16.3 \\
\hline
\end{tabular}

Note. $N=214$ Malaysia; $N=258$ Pakistan.

In fact, participants showed, in general, above average fear of COVID-19. For instance, as reported in Table 1 55.7\% Pakistani and 44.9\% Malaysian students felt uncomfortable thinking about the virus. When considering the impact of the virus, $38.3 \%$ of Pakistan's and $48.6 \%$ of Malaysian students felt COVID-19 was life-threatening. When comparing the two groups overall, students in Malaysia showed a greater level of fear of COVID-19 (63.1\%), and Pakistani students were more fearful when watching COVID-19-related news on social media (61.5\%). The possible reasons students were fearful could be related to their less privileged socioeconomic backgrounds, the threat of family income loss, being located in a COVID-19 red zone, limited access to digital resources, and the high cost of Internet connectivity.

\section{Study 1: Malaysia}

\section{Descriptive Statistics and Correlation}

Table 2 presents the reliability, mean, and standard deviation for each study variable. The results of bivariate correlations show that FCoV was not correlated with mediator PM $(r=0.10, p>0.01)$, but positively correlated with CPSS ( $r=0.18, p<0.01)$. Moreover, it was not correlated with the SPOL $(r=$ $0.03, p>0.01)$. PM is positively and significantly associated with CPSS $(r=0.75, p<0.01)$ and SPOL $(r=0.24, p<0.01)$. Moreover, CPSS was significantly correlated with SPOL $(r=0.30, p<0.01)$. Furthermore, SPOL had no significant relationship with the control variables age and gender.

\section{Table 2}

Cronbach's Alpha, Means, Standard Deviations, and Correlations for the Study Variables

\begin{tabular}{|c|c|c|c|c|c|c|c|c|c|}
\hline Variable & $\begin{array}{c}\text { Cronbach's } \\
a\end{array}$ & $M$ & $S D$ & 1 & 2 & 3 & 4 & 5 & 6 \\
\hline 1. Gender & - & - & - & - & & & & & \\
\hline 2. Age & - & 22.82 & 8.91 & -0.07 & - & & & & \\
\hline 3. $\mathrm{FCoV}$ & 0.89 & 2.73 & 0.88 & 0.13 & -0.08 & - & & & \\
\hline 4. $\mathrm{PM}$ & 0.94 & 2.90 & 0.97 & 0.01 & 0.01 & 0.10 & - & & \\
\hline 5. CPSS & 0.91 & 3.21 & 0.79 & 0.07 & -0.06 & $0.18^{* *}$ & $0.75^{* *}$ & - & \\
\hline 6. SPOL & 0.83 & 3.47 & 0.81 & 0.09 & -0.12 & 0.03 & $0.24^{* *}$ & $0.30^{* * *}$ & - \\
\hline
\end{tabular}

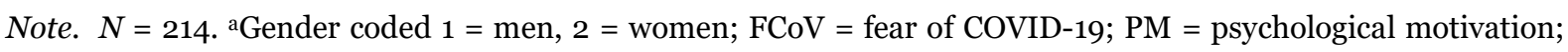
CPSS $=$ cognitive problem-solving skills; SPOL $=$ social presence in online learning. ${ }^{*} p<.05 .{ }^{* *} p<.01$. 


\section{Convergent Validity and Discriminant Validity}

Table 3 shows that the theoretically proposed measurement model (four-factor) has plausibly good fit indices as compared to alternative models. All these indices meet the satisfactory limit (Hu \& Bentler, 1999).

\section{Table 3}

CFA-Model Fit Indices for Study Variables

\begin{tabular}{lcccccccc}
\hline Measurement Model & $\chi^{2}$ & $d f$ & $\chi^{2} / d f$ & CFI & NFI & GFI & TLI & RMSEA \\
\hline $\begin{array}{l}\text { Four-factor model } \\
\text { (hypothesized model: }\end{array}$ & 331.26 & 220 & 1.51 & 0.97 & 0.91 & 0.89 & 0.96 & 0.05 \\
$\quad \begin{array}{l}\text { FCoV, PM, CPSS, \& } \\
\text { SPOL) }\end{array}$ & & & & & & & & \\
$\begin{array}{l}\text { Three-factor model } \\
\text { (PM, CPSS combined FCoV }\end{array}$ & 930.16 & 223 & 4.17 & 0.80 & 0.74 & 0.65 & 0.76 & 0.12 \\
$\quad$ \& SPOL) & & & & & & & & \\
$\begin{array}{l}\text { Two-factor model } \\
\quad \text { combined PM \& CPSS, }\end{array}$ & 1094.25 & 225 & 4.86 & 0.74 & 0.70 & 0.62 & 0.71 & 0.14 \\
$\quad$ combined FCoV \& SPOL) & & & & & & & & \\
$\begin{array}{l}\text { One-factor model } \\
\text { (combined FCoV, PM, }\end{array}$ & 1490.70 & 226 & 6.60 & 0.62 & 0.59 & 0.54 & 0.58 & 0.16 \\
$\quad$ CPSS, \& SPOL) & & & & & & & & \\
\hline
\end{tabular}

Note. CFI = comparative fit index; NFI = normed fit index; GFI = goodness of fit index; TLI = Tucker-Lewis index; RMSEA = root mean square error of approximation; $\mathrm{FCoV}=$ fear of COVID-19; $\mathrm{PM}=$ psychological motivation; $\mathrm{CPSS}=$ cognitive problem-solving skills; $\mathrm{SPOL}=$ social presence in online learning.

Table 4 presents statistics related to reliability and validity. Factor loadings are all greater than 0.5 , average variance extracted (AVE) of all constructs is greater than 0.50 , and composite reliability (CR) is greater than 0.70 for all constructs. In addition, the AVE of each construct is greater than its matching squared correlation coefficient between pairwise latent variables and not equal to 1 . Thus, the results fulfill the criteria of composite reliability, as well as convergent and discriminant validity for the measurement model (Fornell \& Larcker, 1981).

\section{Table 4}

Overall Reliability and Validity of the Constructs

\begin{tabular}{lcccccccc}
\hline Variable & CR & AVE & MSV & MaxR(H) & 1 & 2 & 3 & 4 \\
\hline 1. CPSS & 0.90 & 0.69 & 0.62 & 0.90 & $\mathbf{0 . 8 3}$ & & & \\
2. FCoV & 0.88 & 0.55 & 0.04 & 0.89 & 0.20 & $\mathbf{0 . 7 4}$ & & \\
3. SPOL & 0.89 & 0.54 & 0.10 & 0.90 & 0.32 & 0.05 & $\mathbf{0 . 7 4}$ & \\
4. PM & 0.94 & 0.73 & 0.62 & 0.94 & 0.79 & 0.08 & 0.27 & $\mathbf{0 . 8 6}$ \\
\hline
\end{tabular}


Note: The squared root estimate of AVE are in bold; CR = composite reliability; AVE = average variance extracted; $\mathrm{MSV}=$ maximum shared variance; $\operatorname{MaxR}(\mathrm{H})=$ maximum reliability; $\mathrm{FCoV}=$ fear of COVID-19; $\mathrm{PM}=$ psychological motivation; CPSS = cognitive problem-solving skills; SPOL = social presence in online learning.

\section{Hypotheses Testing}

The SPSS PROCESS macro model 4 was used for hypothesis testing (Hayes \& Preacher, 2013). As shown in Table 5 , results of FCoV were positively and significantly related to CPSS $(\beta=0.17, t=2.77, p=0.00)$ and not related to PM ( $\beta=0.11, t=1.46, p=0.15)$. The CPSS was positively related to the SPOL $(\beta=$ 0.27, $t=2.76, p=0.01)$ when controlling for FCoV, whereas PM had no association with $\operatorname{SPOL}(\beta=-$ $0.04, t=0.45, p=0.65)$. The results of FCoV were not related to students' SPOL $(\beta=0.02, t=0.44, p$ $=0.67)$, rejecting $\mathrm{H} 1$.

\section{Table 5}

Regression Results for Parallel Mediation in Malaysia

\begin{tabular}{lcccc}
\hline \multicolumn{1}{c}{ Variable } & $\beta$ & $S E$ & $t$ & $p$ \\
\hline Direct and total effects & & & & \\
$\quad$ Step 1 & & & & \\
$\quad$ SPOL regressed on FCoV & 0.02 & 0.06 & 0.44 & 0.67 \\
$\quad$ Step 2 & & & & \\
$\quad$ CPSS regressed on FCoV & 0.17 & 0.06 & 2.77 & 0.00 \\
$\quad$ PM regressed on FCoV & 0.11 & 0.08 & 1.46 & 0.15 \\
Step 3 & & & & \\
$\quad$ SPOL regressed on CPSS (after controlling for FCoV) & 0.27 & 0.10 & 2.76 & 0.01 \\
$\quad$ SPOL regressed on PM (after controlling for FCoV) & 0.04 & 0.08 & 0.45 & 0.65 \\
$\quad$ Step 4 & & & & \\
$\quad$ SPOL regressed on FCoV (after controlling for CPSS & -0.02 & 0.06 & -0.36 & 0.72 \\
$\quad$ and PM) & & & & \\
\hline
\end{tabular}

\begin{tabular}{|c|c|c|c|c|}
\hline \multirow[b]{2}{*}{ Bootstrap results for the indirect effect } & \multirow[b]{2}{*}{ Value } & \multirow[b]{2}{*}{$S E$} & \multicolumn{2}{|c|}{$95 \% \mathrm{CI}$} \\
\hline & & & $L L$ & $U L$ \\
\hline The indirect effect of FCoV on SPOL via CPSS & 0.04 & 0.03 & 0.01 & 0.12 \\
\hline The indirect effect of FCoV on SPOL via PM & 0.00 & 0.12 & -0.11 & 0.43 \\
\hline
\end{tabular}

Note. $\mathrm{FCoV}=$ fear of COVID-19; $\mathrm{PM}=$ psychological motivation; $\mathrm{CPSS}=$ cognitive problem-solving skills; $\mathrm{SPOL}=$ social presence in online learning; $\mathrm{CI}=$ confidence interval.

The results indicate that only CPSS fully mediated the relationship between FCoV and students' SPOL $\left(\mathrm{H}_{3}\right)$. As a result, $\mathrm{H}_{2}$ was accepted. In contrast, the results indicate that PM did not mediate the relationship between FCoV and students' SPOL. As a result, $\mathrm{H}_{3}$ was rejected. 


\section{Study 2: Pakistan}

\section{Descriptive Statistics and Correlation}

Table 6 presents the reliability, mean, and standard deviation for each study variable. The results of bivariate correlations show that FCoV was positively correlated with mediators $\mathrm{PM}(r=0.18, p<0.01)$ and CPSS $(r=0.21, p<0.01)$. PM is positively and significantly associated with CPSS $(r=0.69, p<$ 0.01) and students' SPOL $(r=0.54, p<0.01)$. Moreover, CPSS is significantly correlated with the dependent variable, students' SPOL $(r=0.59, p<0.01)$. Furthermore, SPOL has no significant relationship with the control variable age but has a positive and significant relationship with gender $(r$ $=0.26, p<0.01)$.

\section{Table 6}

Cronbach's Alpha, Means, Standard Deviations, and Correlations for the Study Variables

\begin{tabular}{lccccccccc}
\hline Variable & $\begin{array}{c}\text { Cronbach's } \\
\text { alpha }\end{array}$ & $M$ & $S D$ & 1 & 2 & 3 & 4 & 5 & 6 \\
\hline 1. Gendera & - & - & - & - & & & & \\
2. Age & - & 24.47 & 5.24 & -0.10 & - & & & \\
3. FCoV & 0.90 & 2.95 & 0.99 & $0.18^{* *}$ & -0.01 & - & & \\
4. PM & 0.93 & 2.46 & 0.84 & 0.07 & $0.28^{* *}$ & $0.18^{* *}$ & - & \\
5. CPSS & 0.88 & 3.37 & 0.80 & 0.12 & $0.27^{* *}$ & $0.21^{* *}$ & $0.69^{* *}$ & - & \\
6. SPOL & 0.85 & 3.49 & 0.96 & 0.05 & $0.26^{* *}$ & $0.18^{* *}$ & $0.54^{* *}$ & $0.59^{* *}$ & - \\
\hline
\end{tabular}

Note. $N=258 .{ }^{\mathrm{a}}$ Gender coded 1 = men, 2 = women. $\mathrm{FCoV}=$ fear of COVID-19; PM = psychological motivation; CPSS = cognitive problem-solving skills; SPOL = social presence in online learning.

${ }^{*} p<.05 .{ }^{* *} p<0.01$

\section{Convergent Validity and Discriminant Validity}

Table 7 shows that the theoretically built measurement model (four-factor model) established a noticeably better representation of our data, with good fit indices compared to alternative models. It meets the criteria successfully (Hu \& Bentler, 1999).

\section{Table 7}

CFA-Model Fit Indices for Study Variables

\begin{tabular}{lcccccccc}
\hline Measurement model & $\chi^{2}$ & $d f$ & $\chi^{2} / d f$ & CFI & NFI & GFI & TLI & RMSEA \\
\hline $\begin{array}{l}\text { Four-factor model } \\
\text { (hypothesized }\end{array}$ & 336.69 & 180 & 1.87 & 0.95 & 0.90 & 0.89 & 0.95 & 0.06 \\
$\quad$ model: FCoV, PM, & & & & & & & & \\
$\quad$ CPSS, \& SPOL) & & & & & & & & \\
\end{tabular}




\begin{tabular}{|c|c|c|c|c|c|c|c|}
\hline $\begin{array}{l}\text { Three-factor model } \\
\text { (PM, CPSS, } \\
\text { combined FCoV \& } \\
\text { SPOL) }\end{array}$ & 645.65 & 183 & 3.53 & 0.86 & 0.81 & 0.80 & 0.84 \\
\hline $\begin{array}{l}\text { Two-factor model } \\
\text { (combined FCoV, } \\
\text { SPOL \& combined } \\
\text { PM, \& CPSS) }\end{array}$ & 860.27 & 185 & 4.65 & 0.80 & 0.75 & 0.73 & 0.76 \\
\hline $\begin{array}{l}\text { One-factor model } \\
\text { (combined FCoV, } \\
\text { SPOL, PM,\& CPSS) }\end{array}$ & 1308.04 & 186 & 7.03 & 0.66 & 0.62 & 0.61 & 0.61 \\
\hline
\end{tabular}

Note CFI = comparative fit index; NFI = normed fit index; GFI = goodness of fit index; TLI = Tucker Lewis index; RMSEA = root mean square error of approximation; FCoV = fear of COVID-19; PM = psychological motivation; CPSS = cognitive problem-solving skills; SPOL = social presence in online learning.

In Table 8, the convergent validity is shown: factor loadings are all greater than or equal to 0.5 , average variance extracted (AVE) of all constructs is also greater than 0.50 , and composite reliability (CR) is greater than 0.70 for all constructs. In addition, the AVE of each construct is greater than its matching squared correlation coefficient between pairwise latent variables and not equal to 1 . Thus, the results fulfill the criteria of composite reliability, as well as convergent and discriminant validity for the measurement model (Fornell \& Larcker, 1981).

\section{Table 8}

Overall Reliability and Validity of the Constructs

\begin{tabular}{lcccccccc}
\hline Variable & CR & AVE & MSV & MaxR(H) & 1 & 2 & 3 & 4 \\
\hline 1. CPSS & 0.93 & 0.69 & 0.57 & 0.93 & $\mathbf{0 . 8 3}$ & & & \\
2. FCoV & 0.80 & 0.51 & 0.43 & 0.95 & 0.61 & $\mathbf{0 . 7 1}$ & & \\
3. SPOL & 0.89 & 0.57 & 0.05 & 0.96 & 0.20 & 0.20 & $\mathbf{0 . 7 5}$ & \\
4. PM & 0.88 & 0.60 & 0.57 & 0.97 & 0.75 & 0.66 & 0.23 & $\mathbf{0 . 7 7}$ \\
\hline
\end{tabular}

Note: The square root of AVE is shown in bold. $\mathrm{CR}=$ composite reliability; AVE = average variance extracted; MSV = maximum shared variance; $\operatorname{MaxR}(\mathrm{H})=$ maximum reliability; $\mathrm{FCoV}=$ fear of COVID-19; $\mathrm{PM}=$ psychological motivation; CPSS = cognitive problem-solving skills; SPOL = social presence in online learning.

\section{Hypotheses Testing}

The SPSS PROCESS macro model 4 was used for hypothesis testing (Hayes \& Preacher, 2013). As shown in Table 9, results revealed that FCoV was positively and significantly related to $\operatorname{CPSS}(\beta=0.17, t=3.40$, $p=0.00)$ and PM $(\beta=0.15, t=2.93, p=0.00)$. The CPSS $(\beta=0.49, t=5.94, p=0.00)$ and PM $(\beta=$ $0.29, t=3.72, p=0.00$ ) were positively and significantly related to students' SPOL.

The FCoV was positively and significantly associated with students' SPOL. The direct effect of COVID19 on SPOL was insignificant after controlling for CPSS and PM. A bias-corrected bootstrapped test with 5,000 was also run. 


\section{Table 9}

Regression Results for Parallel Mediation in Pakistan

\begin{tabular}{|c|c|c|c|c|}
\hline Variable & $\beta$ & $S E$ & $t$ & $p$ \\
\hline \multicolumn{5}{|l|}{ Direct and total effects } \\
\hline \multicolumn{5}{|l|}{ Step 1} \\
\hline SPOL regressed on FCoV & 0.17 & 0.06 & 2.86 & 0.00 \\
\hline \multicolumn{5}{|l|}{ Step 2} \\
\hline CPSS regressed on FCoV & 0.17 & 0.05 & 3.40 & 0.00 \\
\hline $\mathrm{PM}$ regressed on $\mathrm{FCoV}$ & 0.15 & 0.05 & 2.93 & 0.00 \\
\hline \multicolumn{5}{|l|}{ Step 3} \\
\hline $\begin{array}{l}\text { SPOL regressed on CPSS (after controlling } \\
\text { for FCoV) }\end{array}$ & 0.49 & 0.08 & $5 \cdot 94$ & 0.00 \\
\hline $\begin{array}{l}\text { SPOL regressed on PM (after controlling } \\
\text { for FCoV) }\end{array}$ & 0.29 & 0.08 & 3.72 & 0.00 \\
\hline \multicolumn{5}{|l|}{ Step 4} \\
\hline $\begin{array}{l}\text { SPOL regressed on FCoV (after controlling } \\
\text { for CPSS and PM) }\end{array}$ & 0.04 & 0.05 & 0.91 & 0.36 \\
\hline \multirow{2}{*}{ Bootstrap results for the indirect effect } & \multirow{2}{*}{ Value } & \multirow{2}{*}{$S E$} & \multicolumn{2}{|c|}{$95 \% \mathrm{CI}$} \\
\hline & & & $L L$ & $U L$ \\
\hline The indirect effect of FCoV on SPOL via CPSS & 0.08 & 0.03 & 0.03 & 0.15 \\
\hline The indirect effect of FCoV on SPOL via PM & 0.04 & 0.02 & 0.01 & 0.10 \\
\hline
\end{tabular}

Note. $\mathrm{FCoV}$ = fear of COVID-19; $\mathrm{PM}=$ psychological motivation; CPSS = cognitive problem-solving skills; $\mathrm{SPOL}=$ social presence in online learning.

The results confirmed mediation of CPSS 90\% CI [0.03, 0.15] and PM [0.01, 0.10] because it did not report zero among the lower and upper limits. Moreover, CPSS and PM fully mediated the relationship between FCoV and SPOL.

\section{Discussion}

The COVID-19 pandemic has led to negative emotions, such as fear, and the transition to online learning has caused challenges such as lower levels of academic engagement and social interaction, negatively affecting the psychological state of students (Al-Maroof et al., 2020). This study aimed to investigate the impact of Malaysian and Pakistani students' fear of COVID-19 on SPOL while examining the mediating role of CPSS and PM related to online learning. Fear of COVID-19 is important to study while studying online learning.

As the fear of COVID-19 is a new area of research (Ahorsu et al., 2020; Kassim et al., 2021; Perz et al., 2020), we cannot contrast or corroborate the findings directly with study variables, but we can 
approximate the findings with existing literature. These findings are consistent with existing literature because the fear of COVID-19 has been associated with the students' well-being (Hasan \& Bao, 2020; Kassim et al., 2021).

In study 1 (Malaysia), $\mathrm{H}_{1}$ was not significant, and the results demonstrate that Malaysian students have more resilience than is often assumed (Lee et al., 2021), and that the robust IT infrastructure in Malaysian universities is helping them overcome barriers in online learning (Dhawan, 2020). In study 2 (Pakistan), $\mathrm{H}_{1}$ was significant and it is aligned with a qualitative study conducted in Indonesia that showed students started to get bored with online learning during COVID-19 (Irawan et al., 2020), and that a lack of robust IT infrastructure could be a problem, too (Dhawan, 2020). The $\mathrm{H}_{2}$ was accepted in both studies 1 and 2, and results suggest that cognitive problem-solving skills equip students with the skills to translate their acquired knowledge to solve their routine life problems (Bayrak \& Bayram, 2011).

Similarly, Bayrak and Bayram (2011) found that cognitive problem-solving skills refine students' abilities to make effective decisions, resolve conflicts, and organize information. Online learning assists with the development of cognitive problem-solving skills and students rationalize their knowledge to solve academic problems, which eventually improves students' presence in online learning. $\mathrm{H}_{3}$ was insignificant in study 1 , whereas it was accepted in study 2 . Study 2 results validate the existing findings as students who acquire the knowledge to reflect on their learning are motivated when they have quality interaction with instructors and peers as this increases their satisfaction when facing a real-life problem (Hostetter \& Busch, 2006).

\section{Implications}

The findings of this study do not provide generalizations about remote learning in either Pakistan and Malaysia, but are significant because they provide a deeper understanding of the state of student motivation and coping mechanisms during a pandemic. This study provides a guideline for universities in Malaysia and Pakistan to effectively engage and ensure students' social presence in an online learning environment when facing an uncertain situation such as a pandemic. The study's results emphasize that students' online learning success and active learning are highly dependent on motivation and cognitive skills. Hence, it is recommended to have a robust IT infrastructure and create a well thought out ITintegrated curriculum to develop students' cognitive problem-solving skills and improve psychological motivation.

\section{Conclusion}

The COVID-19 pandemic forced educational institutions to launch a paradigmatic shift in teaching and learning. This study aimed to examine the relationship between COVID-19 fear, students' CPSS, motivation, and students' social presence in online learning in two countries of Asia: Malaysia and Pakistan. The study's findings are significant because they illustrate the psychological impact of the COVID-19 pandemic on students' online learning. The findings highlighted that CPSS is the stimulus behind Malaysian students' interest in online learning. For Pakistani students, psychological motivation and cognitive problem-solving skills positively affect students' manifestation of online learning during the pandemic at the higher education level of learning. 
In future studies, it would be interesting to extend this work and explore larger samples after the postCOVID-19 era. It would be relevant to investigate students' motivation and coping mechanisms among culturally diverse learners. Online learning has become an important part of the higher education system in many countries and future scholars can carry out research on students' social presence in online learning from the perspective of their engagement. 


\section{References}

Adedoyin, O. B., \& Soykan, E. (2020). Covid-19 pandemic and online learning: The challenges and opportunities. Interactive Learning Environments. https://doi.org/10.1080/10494820.2020.1813180

Ahorsu, D. K., Lin, C.-Y., Imani, V., Saffari, M., Griffiths, M. D., \& Pakpour, A. H. (2020). The fear of COVID-19 scale: Development and initial validation. International Journal of Mental Health and Addiction. https://doi.org/10.1007/s11469-020-00270-8

Al-Maroof, R. S., Salloum, S. A., Hassanien, A. E., \& Shaalan, K. (2020). Fear from COVID-19 and technology adoption: The impact of Google Meet during coronavirus pandemic. Interactive Learning Environments, 1-16. https://doi.org/10.1080/10494820.2020.1830121

Amin, I., \& Mariani, S. (2017). PME learning model: The conceptual theoretical study Of metacognition learning In mathematics problem solving based on constructivism. International Electronic Journal of Mathematics Education, 12(3), 333-352. https://www.iejme.com/article/pme-learning-model-the-conceptual-theoretical-study-ofmetacognition-learning-in-mathematics

Baber, H. (2021). Social interaction and effectiveness of the online learning - A moderating role of maintaining social distance during the pandemic COVID-19. Asian Education and Development Studies. Vol. ahead-of-print No. ahead-of-print. https://doi.org/10.1108/AEDS09-2020-0209

Basilaia, G., \& Kvavadze, D. (2020). Transition to online education in schools during a SARS-CoV-2 coronavirus (COVID-19) pandemic in Georgia. Pedagogical Research, 5(4), Article emoo6o. https://doi.org/10.29333/pr/7937

Bayrak, B., \& Bayram, H. (2011). Effects of problem-based learning in a Web environment on conceptual understanding: The subject of acids and bases. International Online Journal of Educational Sciences, 3(3), 831-848. www.iojes.net

Bekele, T. A. (2010). Motivation and satisfaction in Internet-supported learning environments: A review. Educational Technology \& Society, 13(2), 116-127. https://www.jstor.org/stable/jeductechsoci.13.2.116

Bickle, J. T., Hirudayaraj, M., \& Doyle, A. (2019). Social presence theory: Relevance for HRD/VHRD research and practice. Advances in Developing Human Resources, 21(3), 383-399. https://doi.org/10.1177/1523422319851477

Borghans, L., Golsteyn, B. H., \& Zölitz, U. (2015). School quality and the development of cognitive skills between age four and six (Discussion paper No. 9200). Institute for the Study of Labor (IZA). http://hdl.handle.net/10419/114080

Chang, K.-C., Hou, W.-L., Pakpour, A. H., Lin, C.-Y., \& Griffiths, M. D. (2020). Psychometric testing of three COVID-19-related scales among people with mental illness. International Journal of Mental Health and Addiction, 1-13. https://doi.org/10.1007/s11469-020-00361-6 
Daniel, J. (2020). Education and the COVID-19 pandemic. PROSPECTS, 49(1-2), 91-96. https://doi.org/10.1007/s11125-020-09464-3

Dashtestani, R. (2020). Online courses in the higher education system of Iran: A stakeholder-based investigation of pre-service teachers' acceptance, learning achievement, and satisfaction. The International Review of Research in Open and Distributed Learning, 21(4), 117-142. https://doi.org/10.19173/irrodl.v21i4.4873

Dhawan, S. (2020). Online learning: A panacea in the time of COVID-19 crisis. Journal of Educational Technology Systems, 49(1), 5-22. https://doi.org/10.1177/0047239520934018

Dost, S., Hossain, A., Shehab, M., Abdelwahed, A., \& Al-Nusair, L. (2020). Perceptions of medical students towards online teaching during the COVID-19 pandemic: A national cross-sectional survey of 2,721 UK medical students. BMJ Open, 1O(11), Article e042378. https://doi.org/10.1136/bmjopen-2020-042378

Elmer, T., Mepham, K., \& Stadtfeld, C. (2020). Students under lockdown: Comparisons of students' social networks and mental health before and during the COVID-19 crisis in Switzerland. PLOS ONE, 15(7), Article e0236337. https://doi.org/10.1371/journal.pone.0236337

Fornell, C., \& Larcker, D. F. (1981). Evaluating structural equation models with unobservable variables and measurement error. Journal of Marketing Research, 18(1), 39-50. https://doi.org/10.1177/002224378101800104

Gillett-Swan, J. (2017). The challenges of online learning: Supporting and engaging the isolated learner. Journal of Learning Design, 10(1), 20-30. https://doi.org/10.5204/jld.v9i3.293

Grieve, R., Padgett, C. R., \& Moffitt, R. L. (2016). Assignments 2.0: The role of social presence and computer attitudes in student preferences for online versus offline marking. The Internet and Higher Education, 28, 8-16. https://doi.org/10.1016/j.iheduc.2015.08.002

Hasan, N., \& Bao, Y. (2020). Impact of "e-learning crack-up" perception on psychological distress among college students during COVID-19 pandemic: A mediating role of "fear of academic year loss." Children and Youth Services Review, 118, Article 105355. https://doi.org/10.1016/j.childyouth.2020.105355

Hayes, A. F., \& Preacher, K. J. (2013). Conditional process modeling using structural equation modeling to examine contingent causal processes. In G. R. Hancock \& R. O. Mueller (Eds.), Structural Equation Modeling: A Second Course (pp. 219-266). IAP Information Age Publishing. https://psycnet.apa.org/record/2014-01991-006

Hostetter, C., \& Busch, M. (2006). Measuring up online: The relationship between social presence and student learning satisfaction. Journal of Scholarship of Teaching and Learning, 6(2), 1-12. https://eric.ed.gov/?id=EJ854921

Hu, L. T., \& Bentler, P. M. (1999). Cutoff criteria for fit indexes in covariance structure analysis: Conventional criteria versus new alternatives. Structural Equation Modeling: A Multidisciplinary Journal, 6(1), 1-55. https://doi.org/10.1080/10705519909540118 
Huang, C., Wang, Y., Li, X., Ren, L., Zhao, J., Hu, Y., Zhang, L., Fan, G., Xu, J., Gu, X., Cheng, Z., Yu, T., Xia, J., Wei, Y., Wu, W., Xie, X., Yin, W., Li, H., Liu, M., ... Cao, B. (2020). Clinical features of patients infected with 2019 novel coronavirus in Wuhan, China. The Lancet, 395(10223), 497-506. https://doi.org/10.1016/So140-6736(20)30183-5

Irawan, A. W., Dwisona, D., \& Lestari, M. (2020). Psychological impacts of students on online learning during the pandemic COVID-19. KONSELI : Jurnal Bimbingan Dan Konseling (E-Journal), 7(1), 53-60. https://doi.org/10.24042/kons.v7i1.6389

Jonassen, D. H., \& Rohrer-Murphy, L. (1999). Activity theory as a framework for designing constructivist learning environments. Educational Technology Research and Development, 47, 61-79. https://doi.org/10.1007/BFo2299477

Kassim, M. A. M., Pang, N. T. P., Mohamed, N. H., Kamu, A., Ho, C. M., Ayu, F., Rahim, S. S. S. A., Omar, A., \& Jeffree, M. S. (2021). Relationship between fear of COVID-19, psychopathology and sociodemographic variables in Malaysian population. International Journal of Mental Health and Addiction, 1-8. https://doi.org/10.1007/s11469-020-00444-4

Lee, J., Song, H. D., \& Hong, A. J. (2019). Exploring factors, and indicators for measuring students' sustainable engagement in e-learning. Sustainability (Switzerland), 11(4), 985. https://doi.org/10.3390/su11040985

Lee, K., Fanguy, M., Lu, X. S., \& Bligh, B. (2021). Student learning during COVID-19: It was not as bad as we feared. Distance Education, 42(1), 164-172. https://doi.org/10.1080/01587919.2020.1869529

Liu, O. L., Bridgeman, B., \& Adler, R. M. (2012). Measuring learning outcomes in higher education: Motivation matters. Educational Researcher, 41(9), 352-362. https://doi.org/10.3102/0013189X12459679

Mamun, M. A., \& Griffiths, M. D. (2020). A rare case of Bangladeshi student suicide by gunshot due to unusual multiple causalities. Asian Journal of Psychiatry, 49, Article 101951. https://doi.org/10.1016/j.ajp.2020.101951

Masalimova, A. R., Mikhaylovsky, M. N., Grinenko, A. V., Smirnova, M. E., Andryushchenko, L. B., Kochkina, M. A., \& Kochetkov, I. G. (2019). The interrelation between cognitive styles and copying strategies among student youth. Eurasia Journal of Mathematics, Science and Technology Education, 15(4), Article em1695. https://doi.org/10.29333/ejmste/103565

McWhirter, N., \& Shealy, T. (2020). Case-based flipped classroom approach to teach sustainable infrastructure and decision-making. International Journal of Construction Education and Research, 16(1), 3-23. https://doi.org/10.1080/15578771.2018.1487892

Mubarak, A. A., Cao, H., \& Zhang, W. (2020). Prediction of students' early dropout based on their interaction logs in online learning environment. Interactive Learning Environments. https://doi.org/10.1080/10494820.2020.1727529

Noordegraaf-Eelens, L., Kloeg, J., \& Noordzij, G. (2019). PBL and sustainable education: addressing 
the problem of isolation. Advances in Health Sciences Education, 24(5), 971-979. https://doi.org/10.1007/s10459-019-09927-z

Oudeyer, P.-Y., Gottlieb, J., \& Lopes, M. (2016). Intrinsic motivation, curiosity, and learning: Theory and applications in educational technologies. In B. Studer \& S. Knecht (Eds.), Progress in brain research: Vol. 229. Motivation: Theory, neurobiology and applications (pp. 257-284). Elsevier. https://doi.org/10.1016/bs.pbr.2016.05.005

Perz, C. A., Lang, B. A., \& Harrington, R. (2020). Validation of the fear of COVID-19 scale in a US college sample. International Journal of Mental Health and Addiction, 1-11. https://doi.org/10.1007/s11469-020-00356-3

Pramukti, I., Strong, C., Sitthimongkol, Y., Setiawan, A., Pandin, M. G. R., Yen, C.-F., Lin, C.-Y., Griffiths, M. D., \& Ko, N.-Y. (2020). Anxiety and suicidal thoughts during the COVID-19 pandemic: Cross-country comparative study among Indonesian, Taiwanese, and Thai university students. Journal of Medical Internet Research, 22(12), Article e24487. https://doi.org/10.2196/24487

Romero, L., Orzechowski, A., \& Rahatka, O. (2014). Teaching problem-solving and critical-thinking skills online using problem-based learning. Educational Technology, 54(1), 20-25. https://www.jstor.org/stable/44430231

Sakib, N., Bhuiyan, A. K. M. I., Hossain, S., Al Mamun, F., Hosen, I., Abdullah, A. H., Sarker, M. A., Mohiuddin, M. S., Rayhan, I., Hossain, M., Sikder, M. T., Gozal, D., Muhit, M., Islam, S. M. S., Griffiths, M. D., Pakpour, A. H., \& Mamun, M. A. (2020). Psychometric validation of the Bangla fear of COVID-19 scale: Confirmatory factor analysis and Rasch analysis. International Journal of Mental Health and Addiction, 1-12. https://doi.org/10.1007/s11469-020-00289-x

Shapiro, H. B., Lee, C. H., Wyman Roth, N. E., Li, K., Çetinkaya-Rundel, M., \& Canelas, D. A. (2017). Understanding the massive open online course (MOOC) student experience: An examination of attitudes, motivations, and barriers. Computers \& Education, 110, 35-50. https://doi.org/10.1016/j.compedu.2017.03.003

Shea, P., Fredericksen, E., Pickett, A., Pelz, W., \& Swan, K. (2001). Measures of learning effectiveness in the SUNY learning network. In Online Education (pp. 1-24). http://hdl.handle.net/1802/2764

Songkram, N., Khlaisang, J., Puthaseranee, B., \& Likhitdamrongkiat, M. (2015). E-learning system to enhance cognitive skills for learners in higher education. Procedia - Social and Behavioral Sciences, 174, 667-673. https://doi.org/10.1016/j.sbspro.2015.01.599

Stenbom, S. (2018). A systematic review of the community of inquiry survey. The Internet and Higher Education, 39, 22-32. https://doi.org/10.1016/j.iheduc.2018.06.001

Stodel, E. J., Thompson, T. L., \& MacDonald, C. J. (2006). Learners' perspectives on what is missing from online learning: Interpretations through the community of inquiry framework. The International Review of Research in Open and Distributed Learning, 7(3). 
https://doi.org/10.19173/irrodl.v7i3.325

Strong, R. (2012). Investigating students' satisfaction with e-learning courses: The effect of learning environment and social presence. Journal of Agricultural Education, 53(3), 98-110. https://doi.org/10.5032/jae.2012.03098

Woods, R. H., \& Baker, J. D. (2004). Interaction and immediacy in online learning. The International Review of Research in Open and Distributed Learning, 5(2). https://doi.org/10.19173/irrodl.v5i2.186

Zoller, U., \& Pushkin, D. (2007). Matching higher-order cognitive skills (HOCS) promotion goals with problem-based laboratory practice in a freshman organic chemistry course. Chemistry Education Research and Practice, 8(2), 153-171. https://doi.org/10.1039/B6RP90028C

Zolotov, Y., Reznik, A., Bender, S., \& Isralowitz, R. (2020). COVID-19 fear, mental health, and substance use among Israeli university students. International Journal of Mental Health and Addiction, 1-7. https://doi.org/10.1007/s11469-020-00351-8 


\section{Appendix 1}

Here are the items surveyed in each category of variable.

\section{Students' Social Presence in Online Learning}

1. The instructor facilitated discussions in the course.

2. I felt comfortable interacting with other participants in the online course.

3. I felt comfortable participating in the course discussions.

4. I felt comfortable conversing through this text-based medium.

5. Computer-mediated communication is an excellent medium for social interaction.

6. The instructor created a feeling of an online community

7. I was able to form distinct individual impressions of some course participants even though we communicated only via a text-based medium.

8. The introductions enabled me to form a sense of online community.

9. Discussions using the medium of computer-mediated communication tend to be more impersonal than face-to-face discussions.

10. I felt my point of view was acknowledged by other participants in the course.

11. I felt comfortable introducing myself in the online course.

12. Computer-mediated communication is more impersonal than video teleconference discussions.

13. Computer-mediated communication is more impersonal than audio teleconference discussions.

14. Messages in the online course were impersonal.

\section{Psychological Motivation}

1. Online classes enhance my interest in learning.

2. I am motivated to study when I take an online class.

3. Online classes are useful to me.

4. It is interesting to take online classes.

5. After taking an online lesson, I look forward to the next one.

6. I am satisfied with the online class I am taking. 


\section{Cognitive Problem-Solving Skills}

1. I can derive new interpretations and ideas from the knowledge I have learned in my online classes.

2. I can deeply analyze thoughts, experiences, and theories about the knowledge I have learned in my online classes.

3. I can judge the value of the information related to the knowledge learned in my online classes.

4. I tend to apply the knowledge I have learned in online classes to real problems or new situations.

5. I try to approach the subject of my online class with a new perspective.

\section{Fear of COVID-19}

1. I am most afraid of coronavirus-19.

2. It makes me uncomfortable to think about coronavirus-19.

3. My hands become clammy when I think about coronavirus-19.

4. I am afraid of losing my life because of coronavirus-19.

5. When watching news and stories about coronavirus-19 on social media, I become nervous or anxious.

6. I cannot sleep because I am worried about getting coronavirus-19.

7. My heart races or palpitates when I think about getting coronavirus-19.

\section{Athabasca}

University

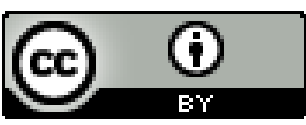

